\title{
Penerapan Hidden Markov Model Pada Harga Saham
}

\author{
Sri Wahyuni Mamonto ${ }^{1}$, Yohanes A. R. Langi ${ }^{2}$, Altien J. Rindengan ${ }^{3}$ \\ ${ }^{1}$ Program Studi Matematika, FMIPA, UNSRAT Manado, mamontosri@gmail.com \\ ${ }^{2}$ Program Studi Matematika, FMIPA, UNSRAT Manado, yarlangi@ gmail.com \\ ${ }^{3}$ Program Studi Matematika, FMIPA, UNSRAT Manado, altien@unsrat.ac.id
}

\begin{abstract}
Abstrak
Hidden Markov Model (HMM) adalah perkembangan dari rantai Markov di mana statenya tidak dapat diamati secara langsung (tersembunyi), tetapi hanya dapat diobservasi melalui suatu himpunan pengamatan lain. Tujuan dari penelitian ini untuk memprediksi peluang kenaikan harga saham PT. Bank BNI Tbk, PT. Bank BRI Tbk, PT. Bank BTN Tbk, dan PT. Bank Mandiri Tbk dengan menggunakan Algoritma Baum Welch dalam Hidden Markov Model dan untuk memprediksi state tersembunyi (peluang naik turunnya) suatu harga saham dari PT. Bank BNI Tbk, PT. Bank BRI Tbk, PT. Bank BTN Tbk, dan PT. Bank Mandiri Tbk pada tahun 2016 dengan menggunakan decoding problem. Penelitian ini menggunakan data harga saham harian dengan periode satu minggu, satu bulan, dan satu tahun. Data yang digunakan yaitu data sekunder dari harga saham harian (penutupan) PT. Bank BNI Tbk, PT. Bank BRI Tbk, PT. Bank BTN Tbk, dan PT. Bank Mandiri Tbk untuk memprediksi peluang kenaikan harga saham dengan periode satu minggu, satu bulan dan satu tahun pada tahun 2016. Dari hasil penelitian menunjukkan bahwa Hidden Markov Model dapat digunakan untuk memprediksi peluang kenaikan harga saham dan hasil prediksi peluang kenaikan harga saham yang paling tinggi untuk satu minggu dan satu bulan yaitu PT. Bank Mandiri Tbk, sedangkan untuk satu tahun di tahun 2016 adalah harga saham PT. Bank BRI Tbk yang hanya selisih peluang sekitar 0.2 dengan bank lain. Pada algoritma Viterbi, dapat di ambil kesimpulan bahwa untuk 2016 kemungkinan harga saham dari bank PT. Bank BNI Tbk, PT. Bank BRI Tbk, PT. Bank BTN Tbk, dan PT. Bank Mandiri Tbk akan lebih banyak turun, walaupun akan lebih banyak turun tidak akan menutup kemungkinan untuk peluang kenaikan harga saham PT. Bank BRI Tbk pada tahun 2016 akan mengalami kenaikan.
\end{abstract}

Kata kunci : Hidden Markov Model, Saham Bank.

\section{Application Of Hidden Markov Models In Stock Prices}

\begin{abstract}
Hidden Markov Model (HMM) is the development of a Markov chain in which its state can not be observed directly (hidden), but can only be observed through a set of other observations. The purpose of this study to predict the chances of rising stock prices PT. Bank BNI Tbk, PT. Bank BRI Tbk, PT. Bank BTN Tbk, and PT. Bank Mandiri Tbk using Baum Welch algorithm in the Hidden Markov Model and to predict the hidden state (opportunities rise and fall) of a share price of PT. Bank BNI Tbk, PT. Bank BRI Tbk, PT. Bank BTN Tbk, and PT. Bank Mandiri Tbk in 2016 using a decoding problem. This study uses data daily stock price with a period of one week, one month and one year. The data used is secondary data from daily stock price (closing) PT. Bank BNI Tbk, PT. Bank BRI Tbk, PT. Bank BTN Tbk, and PT. Bank Mandiri Tbk to predict the chances of rising stock prices with the period of one week, one month and one year in 2016. The results showed that the Hidden Markov Models can be used to predict the chances of rising stock prices and yield prediction of stock price increase chances highest for one week and one month, namely PT. Bank Mandiri Tbk, while for the year 2016 is the price of shares. Bank BRI Tbk is only around 0.2 margin opportunities with other banks. In the Viterbi algorithm, can take the conclusion that for 2016 the possibility of the stock price of the bank PT. Bank BNI Tbk, PT. Bank BRI Tbk, PT. Bank BTN Tbk, and PT. Bank Mandiri Tbk will be more down, although it will be more down would not rule out the possibility of price increases chances shares. Bank BRI Tbk in 2016 will increase.
\end{abstract}

Keywords: Hidden Markov Model, Bank Stocks. 


\section{Pendahuluan}

Peramalan dalam investasi saham menjadi tugas yang sulit dikarenakan kekompleksan, keberagaman dan non-linear datanya. Fluktuasi dari harga saham selalu dipengaruhi oleh banyak faktor, seperti interest rate, keadaan suatu negara, keadaan perusahaan, dan sebagainya. Investor tidak dapat secara terus-menerus mendapatkan keuntungan selama berinvestasi saham, dikarenakan hal tersebut banyak dibuat peramalan harga saham untuk memudahkan investor membuat keputusan dalam berinvestasi [1].

Hidden Markov Model (HMM) adalah peluasan dari rantai Markov di mana statenya tidak dapat diamati secara langsung (tersembunyi), tetapi hanya dapat diobservasi melalui suatu himpunan pengamatan lain. Pada Hidden Markov Model terdapat tiga permasalahan mendasar yang harus diselesaikan yakni evaluation problem, decoding problem, dan learning problem [2].

Telah dilakukan penelitian tentang peramalan harga harian saham untuk mempermudah investor dalam berinvestasi saham dengan mengurangi resiko yang ada [1]. Dalam penelitian ini akan memprediksi peluang kenaikan harga saham untuk periode satu minggu, satu bulan, dan satu tahun kedepan menggunakan Hidden Markov Model dengan evaluation, decoding dan learning prolem, penggunaan hasil prediksi peluang kenaikan harga saham memberikan kemudahan untuk mengambil keputusan dalam berinvestasi saham.

\section{Proses Stokastik}

Proses stokastik $\mathrm{X}=\{X(t), t \in T\}$ adalah suatu koleksi (gugus, himpunan, atau kumpulan) dari peubah acak yang memetakan suatu ruang contoh ke suatu ruang state. Jadi, untuk setiap $t$ pada gugus (himpunan) indeks T, $X(t)$ adalah suatu peubah acak. Dengan $t$ sebagai waktu, dan $X(t)$ kita sebut sebagai state (keadaan) dari proses pada waktu $t$. Sehingga proses $X=\{X(t), t \in T\}$ adalah proses pada state $\mathrm{x}$ pada waktu $t$, jika kejadian $\{X(t)=x\}$ telah terjadi [3].

\section{Hidden Markov Model}

Hidden Markov Model adalah sebuah proses stokastik ganda di mana salah satu prosesnya tidak dapat diobservasi (hidden). Proses hidden ini hanya dapat diamati melalui proses yang dapat diobservasi. Jika $X=\left\{X_{1}, X_{2}, \ldots,\right\}$ adalah sebuah proses markov, dan $O=\left\{O_{1}, O_{2}, \ldots\right\}$ adalah fungsi dari $X$, maka $X$ adalah sebuah Hidden Markov Model yang dapat diobservasi melalui $O$, atau dapat ditulis $O=f(X)$ untuk suatu fungsi $f$. Parameter $X$ menyatakan state process yang tersembunyi (hidden), sementara parameter $O$ menyatakan observation process yang dapat diobservasi [4].

Elemen-elemen dari Hidden Markov Model adalah:

1) $\mathrm{N}$, yaitu jumlah state, dengan ruang state $S=\left\{s_{1}, s_{2}, \ldots, s_{n}\right\}$ dan state pada waktu t dinyatakan dengan $Q_{t}$.

2) $\mathrm{M}$, yaitu jumlah pengamatan (observasi) tiap state, dengan ruang observasi $V=\left\{v_{1}, v_{2}, \ldots, v_{m}\right\}$.

3) $A=\left[a_{i j}\right]$, yaitu matriks peluang transisi.

4) $B=\left[b_{j m}\right]$, yaitu matriks peluang bersyarat observasi $v_{m}$ jika proses berada pada state $\mathrm{j}$, dimana:

$b_{j m}=b_{j}\left(O_{t}\right)=P\left(O_{t}=v_{m} \mid Q_{t}=s_{j}\right), 1 \leq j \leq N$ dan $1 \leq m \leq M$

5) $\pi_{i}$ yaitu distribusi state awal [5].

Ada tiga permasalahan khusus yang dapat diselesaikan oleh metode Hidden Markov Model, yaitu :

a) Evaluation Problem

Pengertian dari operasi evaluasi masalah dalam Hidden Markov Model adalah perhitungan probabilitas dari urutan nilai observasi yang diberikan oleh Hidden Markov Model. Masalah ini dapat diselesaikan dengan algoritma Forward dan Backward [6]. 
Langkah-langkah penyelesaian dengan algoritma Forward adalah sebagai berikut[6].

i. Inisialiasasi : $\quad \alpha_{i}(i)=\pi(i) b_{i}\left(O_{1}\right)$ dimana $1 \leq i \leq N$

ii. Induksi : $\quad \alpha_{t+1}(j)=\left\{\sum_{i=1}^{N} \alpha_{t}(i) a_{i j}\right\} b_{j}\left(O_{t+1}\right)$

iii. Akhir : $\quad P(O \mid \lambda)=\sum_{i=1}^{N} \alpha_{T}(i)$

Sedangkan untuk algoritma backward langkah-langkahnya adalah sebagai berikut[6]:

i. Inisialisasi : $\quad \beta_{T}(i)=1$ untuk $i=1,2, \ldots, N$

ii. Induksi : $\quad \beta_{t}(i)=\sum_{j=1}^{N} b_{j}\left(O_{t+1}\right) \beta_{t+1}(j) a_{i j}$

Untuk $t=T-1, T-2, \ldots, 1$ dan $i=1,2, \ldots, N$

iii. Akhir $\quad: \quad P(O \mid \lambda)=\sum_{i=1}^{N} b_{i}\left(O_{1}\right) \pi(i) \beta_{1}(i)$

b) Decoding Problem

Pengertian dari decoding problem dalam Hidden Markov Model adalah penarikan kesimpulan berdasarkan asumsi yang diperoleh dari nilai probabilitas observasi yang didapat sebelumnya pada operasi evaluasi. Operasi ini juga sering kali digunakan untuk mencari nilai optimum. Masalah ini dapat diselesaikan dengan Algoritma Viterbi.

Langkah-langkah dalam algoritma Viterbi untuk menentukan barisan state terbaik yaitu [6] :

i. Inisialisasi : $\quad \delta_{1}(i)=\pi_{i} b_{i}\left(O_{1}\right)$ dimana $1 \leq i \leq N$

ii. Rekursi :

$$
\psi_{1}(i)=0
$$

$$
\begin{aligned}
& \delta_{t}(i)=\underset{1 \leq i \leq N}{\max }\left[\delta_{t-1}(i) a_{i j}\right] b_{j}\left(O_{t}\right), 2 \leq t \leq T, 1 \leq j \leq N \\
& \psi_{1}(i)={ }_{1 \leq i \leq N}^{\arg \max }\left[\delta_{t-1}(i) a_{i j}\right], 2 \leq t \leq T, 1 \leq j \leq N \ldots \ldots \ldots
\end{aligned}
$$

iii. State terbaik pada waktu $\mathrm{T}\left(Q_{T}\right): P^{*}=\max _{1 \leq i \leq N}\left[\delta_{T}(i)\right]$

$$
Q^{*}{ }_{T}=\underset{1 \leq i \leq N}{\arg \max }\left[\delta_{t}(i)\right]
$$

iv. Barisan state terbaik pada $\mathrm{t}=\mathrm{T}-1, \mathrm{~T}-2, \ldots, 1$

$$
Q^{*}{ }_{t}=\psi_{t+1}\left(Q^{*}{ }_{t+1}\right), t=T-1, T-2, \ldots, 1
$$

\section{c) Learning Problem}

Pengertian dari operasi learning dalam Hidden Markov Model adalah membuat parameterparameter baru Hidden Markov Model jika diberikan dataset barisan-barisan tertentu agar dapat menemukan himpunan transisi state yang paling mungkin beserta probabilitas hasilnya.

Dalam algoritma Baum-Welch, didefinisikan empat variabel, yaitu : variabel forward diberikan oleh persamaan (2)-(4), variabel backward juga telah didefinisikan pada persamaan (5)(7), variabel $\xi_{t}(i, j)$, dan variabel $\gamma_{t}(i)$. Variabel forward dan variabel backward akan digunakan dalam perhitungan variabel $\xi_{t}(i, j)$ dan variabel $\gamma_{t}(i)$. Sehingga rumus estimasi learning problem sebagai berikut [6] :

$$
\begin{aligned}
& \hat{\pi}=\gamma_{1}(i), \quad 1 \leq i \leq N \\
& \hat{a}_{i j}=\frac{\sum_{t=1}^{T-1} \xi_{t}(i, j)}{\sum_{t=1}^{T-1} \gamma_{t}(i)}, \quad 1 \leq i \leq N, 1 \leq j \leq N \\
& \hat{b}_{j}(k)=\frac{\sum_{t=1}^{T}, o_{t=k} \gamma_{t}(j)}{\sum_{t=1}^{T} \gamma_{t}(j)}, \quad 1 \leq j \leq N, 1 \leq k \leq M
\end{aligned}
$$

\section{Metodologi Penelitian}

\subsection{Waktu dan Tempat Penelitian}

Penelitian dilaksanakan pada bulan Februari 2016 sampai April 2016 di Laboratorium Statistika Program Studi Matematika Fakultas MIPA Universitas Sam Ratulangi.

\subsection{Populasi dan Sampel Penelitian}

Populasi yang digunakan dalam penelitian ini adalah semua saham bank di Indonesia, dengan empat saham bank yang akan dijadikan sebagai sampel yaitu saham Bank BNI, BRI, BTN dan Mandiri, ke empat bank ini merupakan perusahaan BUMN publik dengan saham paling tertinggi di bandingkan saham bank lain. 


\subsection{Data dan Variabel Penelitian}

Dalam penelitian ini data saham yang akan digunakan hanya data saham satu tahun yaitu tahun 2015 , pada tanggal 1 Januari 2015 sampai 31 Desember 2015 dengan periode satu minggu, satu bulan dan satu tahun, dari data harga saham penutupan pada Bank BNI, BRI, BTN dan Mandiri, yang diperoleh di alamat website https://beta.finance.yahoo.com dengan banyaknya data yang akan di gunakan dalam satu bank adalah 260.

Variabel yang akan digunakan adalah data saham harian bank BNI, BRI, BTN, dan Mandiri yang akan di buat dalam bentuk peluang, sehingga akan membentuk sebuah matriks $3 \times 4$ untuk matriks observasi dan transisinya. Dengan state 4 yaitu saham dari bank BNI, BRI, BTN dan Mandiri, dimana masing-masing harga saham dari bank BNI, BRI, BTN dan Mandiri akan dibentuk matriks observasi, matriks transisi serta matriks awal.

\subsection{Metode Analisis}

Dalam penelitian ini menggunakan Hidden Markov Model. Yang akan di analisis adalah data harga saham dari bank BNI, BRI, BTN, Mandiri dengan menghasilkan prediksi kemungkinan harga saham untuk bank BNI, BRI, BTN dan Mandiri. Adapun langkah-langkah analisisnya adalah sebagai berikut :

1) Pengambilan data harga saham bank BNI, BRI, BTN, dan Mandiri.

2) Mencari matriks peluang yang dibutuhkan dari bank BNI, BRI, BTN, dan Mandiri dengan menggunakan persamaan (1)-(3) dan dibuat dalam bentuk peluang dengan menggunakan rumus peluang sebagai berikut.

$$
P(A)=\frac{n(A)}{n(s)}
$$

3) Menentukan elemen-elemen Hidden Markov Model.

4) Menganalisis elemen-elemen Hidden Markov Model yang telah di dapat dengan menggunakan tiga permasalahan dalam Hidden Markov Model yaitu Evaluation Problem, Decoding Problem dan Learning Problem.

5) Melakukan prediksi menggunakan Evaluation Problem dengan Algoritma Forward dan Backward, Decoding Problem dengan Algoritma Viterbi dan Learning Problem dengan Algoritma Baum-Welch dalam Hidden Markov Model .

6) Membuat interpretasi atau kesimpulan dari hasil yang telah didapatkan dengan jelas.

\section{Hasil dan Pembahasan}

\subsection{Element - Element Dari Hidden Markov Model}

1. N yaitu jumlah state tersembunyi, dengan ruang state $S=\left\{s_{1}, s_{2}, \ldots, s_{n}\right\}$ dan state pada waktu t dinyatakan dengan $Q_{t}$. Untuk kasus harga saham dari bank BNI, BRI, BTN, dan Mandiri. Keadaan tersembunyinya adalah naik, turun dan tetap, sehingga pada studi kasus ini $\mathrm{N}=3$. Atau dapat ditulis 1(naik), 2(turun) dan 3(tetap).

2. $\mathrm{M}$, yaitu jumlah pengamatan (observasi) tiap state, dengan ruang observasi $V=\left\{v_{1}, v_{2}, \ldots, v_{m}\right\}$, dalam penelitian ini elemennya ada 4 , yaitu bank BNI, BRI, BTN dan Mandiri.

3. $A=\left[a_{i j}\right]$, yaitu matriks peluang transisi dari bank BNI, BRI, BTN, dan Mandiri, jadi masingmasing setiap bank mempunyai matriks transisi yaitu sebagai berikut :

a) Matriks transisi untuk bank BNI

b) Matriks transisi untuk bank BRI

$$
A=\left[a_{i j}\right]=\left[\begin{array}{ccc}
0.4 & 0.47 & 0.13 \\
0.4 & 0.46 & 0.14 \\
0.38 & 0.41 & 0.22
\end{array}\right]
$$

$$
A=\left[a_{i j}\right]=\left[\begin{array}{lll}
0.46 & 0.41 & 0.13 \\
0.42 & 0.49 & 0.09 \\
0.41 & 0.32 & 0.26
\end{array}\right]
$$


c) Matriks transisi untuk bank BTN

d) Matriks transisi untuk bank Mandiri

$$
A=\left[a_{i j}\right]=\left[\begin{array}{lll}
0.37 & 0.49 & 0.14 \\
0.48 & 0.36 & 0.17 \\
0.39 & 0.36 & 0.25
\end{array}\right]
$$

$$
A=\left[a_{i j}\right]=\left[\begin{array}{lll}
0.43 & 0.45 & 0.12 \\
0.42 & 0.42 & 0.16 \\
0.33 & 0.46 & 0.21
\end{array}\right]
$$

4. $B=\left[b_{j m}\right]$, yaitu matriks peluang bersyarat observasi $v_{m}$ jika proses berada pada state $\mathrm{j}$, matriks observasi untuk bank BNI, BRI, BTN, dan Mandiri adalah sebagai berikut :

$$
B=\left[b_{j m}\right]=\left[\begin{array}{llll}
0.24 & 0.26 & 0.27 & 0.25 \\
0.24 & 0.25 & 0.26 & 0.24 \\
0.28 & 0.25 & 0.23 & 0.27
\end{array}\right]
$$

5. $\pi_{i}$ yaitu distribusi state awal, untuk kasus harga saham tersebut di asumsikan :

$\pi(1)=P($ naik $), \pi(2)=P($ turun $), \pi(3)=P($ tetap $)$. Matriks awal untuk bank BNI, BRI,

BTN, dan bank Mandiri sebagai berikut.
a). Matriks awal untuk bank BNI $: \pi=\left[\begin{array}{c}0.4 \\ 0.45 \\ 0.15\end{array}\right]$
b). Matriks awal untuk bank BRI $: \pi=\left[\begin{array}{l}0.43 \\ 0.43 \\ 0.13\end{array}\right]$
c). Matriks awal untuk bank BTN $: \pi=\left[\begin{array}{l}0.42 \\ 0.41 \\ 0.17\end{array}\right]$
d). Matriks awal untuk bank Mandiri $\quad: \pi=\left[\begin{array}{c}0.41 \\ 0.44 \\ 0.15\end{array}\right]$

\subsection{Evaluation Problem Dengan Algoritma Forward dan Backward}

Di asumsikan barisan observasi yang memiliki peluang dengan kenaikan harga saham tertinggi untuk keempat bank berturut-turut adalah BRI, BNI, Mandiri, dan BTN. Untuk permasalahan pertama pada $\mathrm{HMM}$, akan dihitung peluang model $\lambda=(\mathrm{A}, \mathrm{B}, \pi)$ pada bank BNI yang menghasilkan barisan observasi $\mathrm{O}=\{\mathrm{BRI}, \mathrm{BNI}$, Mandiri, BTN $\}$. Berikut ini tahap akhir dengan algoritma forward dan backward.

$$
\begin{aligned}
& P(O=B R I, B N I, \text { Mandiri, } B T N \mid \lambda)=\sum_{i=1}^{N} \alpha_{T}(i) \\
& \quad=\alpha_{5}(1)+\alpha_{5}(2)+\alpha_{5}(3)=4 \times 10^{-4}+5 \times 10^{-4}+1 \times 10^{-4}=0.001 \\
& P(O=B R I, B N I, \text { Mandiri, BTN } \mid \lambda)=\sum_{i=1}^{N} b_{i}\left(O_{1}\right) \pi(i) \beta_{1}(i) \\
& \quad=b_{1}\left(O_{1}\right) \pi(1) \beta_{1}(1)+b_{2}\left(O_{1}\right) \pi(2) \beta_{1}(2)+b_{3}\left(O_{1}\right) \pi(3) \beta_{1}(3) \\
& \quad=(0.26)(0.4)(0.004)+(0.25)(0.45)(0.004)+(0.25)(0.15)(0.004)=0.001
\end{aligned}
$$

Hasil dari algoritma mundur konsisten dengan yang diperoleh dari algoritma maju, atau hasil algoritma mundur sama dengan hasil dari algoritma maju yaitu 0.001. Maka kemungkinan peluang kenaikan harga saham berurutan yaitu BRI, BNI, Mandiri, dan BTN akan terjadi adalah 0.001 .

Sedangkan untuk bank BRI, BTN dan Mandiri mempunyai hasil Algoritma Forward dan Backward yang sama seperti pada bank BNI dengan observasi yang sama yaitu BRI, BNI, Mandiri, dan BTN peluang kemungkinan akan terjadi yaitu 0.001 .

\subsection{Decoding Problem Dengan Algoritma Viterbi}

Untuk Permasalahan decoding problem ini adalah bagaimana menentukan barisan hidden state yang optimal dalam hal ini yaitu naik, turun atau tetapnya harga saham suatu bank, sesuai dengan barisan observasi yang telah diasumsikan. Setelah diberikan barisan observasi berturutturut BRI, BNI, Mandiri, BTN dengan menggunakan algoritma viterbi didapatkan barisan keadaan tersembunyi yang paling optimal untuk bank BNI, BRI, Mandiri dan BTN yaitu : 
$Q^{*}{ }_{1}=2, Q^{*}{ }_{2}=2, Q^{*}{ }_{3}=2, Q^{*}{ }_{4}=2$ yang artinya barisan naik, turun atau tetapnya harga saham yang paling mungkin untuk tahun 2016 akan lebih banyak turun.

\subsection{Learning Problem Dengan Algoritma Baum-Welch}

Berdasarkan dari algoritma Forward dan backward, dengan menggunakan informasi yang sama seperti pada algoritma Forward dan backward akan dicari penaksir parameter untuk $\hat{\lambda}=$ $(\hat{A}, \widehat{B}, \hat{\pi})$. Learning Problem dengan Algoritma Baum-Welch Untuk bank BNI, BRI, BTN dan bank Mandiri adalah sebagai berikut.

a). Bank BNI

$$
\hat{\pi}=\left[\begin{array}{l}
Y_{1}(1) \\
Y_{1}(2) \\
Y_{1}(3)
\end{array}\right]=\left[\begin{array}{l}
0.408 \\
0.446 \\
0.146
\end{array}\right]
$$

Nilai pada $\gamma_{t}(i)$ untuk $\mathrm{t}=1$ merupakan taksiran peluang awal. Artinya agar nilai $P(O \mid \widehat{\lambda}) \geq$ $P(O \mid \lambda)$ terpenuhi, maka probabilitas proses berada pada state harga saham akan naik adalah sebesar 0.408 , peluang harga saham akan turun adalah sebesar 0.446 dan taksiran peluang awal bahwa proses berada pada harga saham tetap adalah sebesar 0.146 .

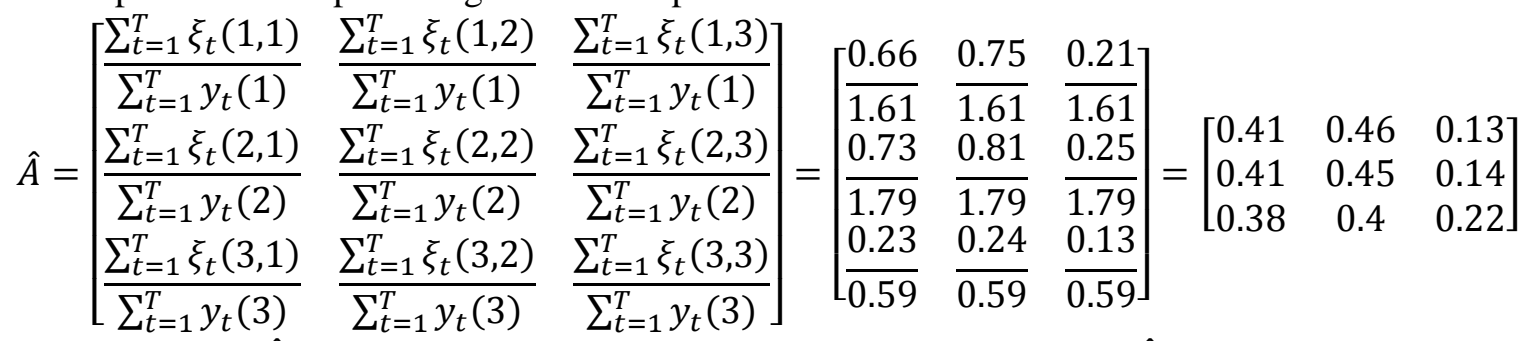

Matriks $\hat{A}$ merupakan penaksir untuk matriks transisi A. Matriks $\hat{A}$ menggambarkan bahwa untuk mencapai nilai $P(O \mid \widehat{\lambda}) \geq P(O \mid \lambda)$ maka probabilitas transisi harga saham dari "naik" ke "naik" adalah 0.41, dari "naik" ke "turun" sebesar 0.46, dari "naik" ke "tetap" sebesar 0.13, dan dari "turun" ke "naik" sebesar 0.41, dari "turun" ke "turun" sebesar 0.45 , dari "turun" ke "tetap" sebesar 0.14, serta dari "tetap" ke "naik" sebesar 0.38, dari "tetap" ke "turun" sebesar 0.4, dari "tetap" ke "tetap" sebesar 0.22 .

$$
\begin{gathered}
\hat{B}=\left[\begin{array}{llll}
\frac{\sum_{t=1, o_{t}=1}^{T} y_{t}(1)}{\sum_{t=1}^{T} y_{t}(1)} & \frac{\sum_{t=1, o_{t}=2}^{T} y_{t}(1)}{\sum_{t=1}^{T} y_{t}(1)} & \frac{\sum_{t=1, o_{t}=3}^{T} y_{t}(1)}{\sum_{t=1}^{T} y_{t}(1)} & \frac{\sum_{t=1, o_{t}=4}^{T} y_{t}(1)}{\sum_{t=1}^{T} y_{t}(1)} \\
\frac{\sum_{t=1, o_{t}=1} y_{t}(2)}{\sum_{t=1}^{T} y_{t}(2)} & \frac{\sum_{t=1, o_{t}=2}^{T} y_{t}(2)}{\sum_{t=1}^{T} y_{t}(2)} & \frac{\sum_{t=1, o_{t}=3}^{T} y_{t}(2)}{\sum_{t=1}^{T} y_{t}(2)} & \frac{\sum_{t=1, o_{t}=4}^{T} y_{t}(2)}{\sum_{t=1}^{T} y_{t}(2)} \\
\frac{\sum_{t=1, o_{t}=1}^{T} y_{t}(3)}{\sum_{t=1}^{T} y_{t}(3)} & \frac{\sum_{t=1, o_{t}=2}^{T} y_{t}(3)}{\sum_{t=1}^{T} y_{t}(3)} & \frac{\sum_{t=1, o_{t}=3}^{T} y_{t}(3)}{\sum_{t=1}^{T} y_{t}(3)} & \frac{\sum_{t=1, o_{t}=4}^{T} y_{t}(3)}{\sum_{t=1}^{T} y_{t}(3)}
\end{array}\right] \\
=\left[\begin{array}{lllll}
\frac{0.408}{1.61} & \frac{0.389}{1.61} & \frac{0.402}{1.61} & \frac{0.415}{1.61} \\
\frac{0.446}{1.79} & \frac{0.446}{1.79} & \frac{0.441}{1.79} & \frac{0.457}{1.79} \\
\frac{0.146}{0.59} & \frac{0.164}{0.59} & \frac{0.156}{0.59} & \frac{0.128}{0.59}
\end{array}\right]=\left[\begin{array}{llll}
0.25 & 0.24 & 0.25 & 0.26 \\
0.25 & 0.25 & 0.25 & 0.26 \\
0.25 & 0.28 & 0.26 & 0.22
\end{array}\right]
\end{gathered}
$$

Matriks $\hat{B}$ merupakan penaksir untuk matriks emisi B. untuk mencapai nilai $P(O \mid \widehat{\lambda}) \geq$ $P(O \mid \lambda)$ maka peluang kenaikan harga saham bank pada periode 1 minggu kedepan untuk saham bank BNI adalah sebesar 0.25, untuk saham BRI sebesar 0.24, untuk saham BTN sebesar 0.25, untuk saham Mandiri sebesar 0.26. Peluang kenaikan harga saham bank pada periode 1 Bulan kedepan untuk saham bank BNI adalah sebesar 0.25, untuk saham BRI sebesar 0.25, untuk saham BTN sebesar 0.25, untuk saham Mandiri sebesar 0.26. Dan peluang kenaikan harga saham bank pada periode 1 tahun kedepan untuk saham bank BNI adalah sebesar 0.25, untuk saham BRI sebesar 0.28, untuk saham BTN sebesar 0.26, untuk saham Mandiri sebesar 0.22. 
Algoritma Baum-Welch untuk matriks $\hat{B}$ pada bank BRI, BTN, dan Mandiri mempunyai hasil yang persis sama seperti pada bank BNI, dengan hasil perhitungan untuk matriks peluang awal dan matriks transisi pada bank BRI, BTN dan Mandiri sebagai berikut.

b). Bank BRI

c). Bank BTN

$$
\hat{\pi}=\left[\begin{array}{c}
0.444 \\
0.42 \\
0.135
\end{array}\right] ; \hat{A}=\left[\begin{array}{ccc}
0.47 & 0.4 & 0.14 \\
0.43 & 0.48 & 0.09 \\
0.41 & 0.32 & 0.27
\end{array}\right]
$$

d). Bank Mandiri

$$
\hat{\pi}=\left[\begin{array}{l}
0.423 \\
0.405 \\
0.173
\end{array}\right] ; \hat{A}=\left[\begin{array}{lll}
038 & 0.48 & 0.14 \\
0.48 & 0.35 & 0.17 \\
0.39 & 0.36 & 0.25
\end{array}\right]
$$

$$
\hat{\pi}=\left[\begin{array}{l}
0.415 \\
0.432 \\
0.153
\end{array}\right] ; \hat{A}=\left[\begin{array}{lll}
0.43 & 0.44 & 0.13 \\
0.43 & 0.41 & 0.16 \\
0.38 & 0.45 & 0.21
\end{array}\right]
$$

Berdasarkan penerapan Hidden Markov Model pada harga saham pada penelitian ini, Hidden Markov Model dapat memprediksi satu minggu, satu bulan dan satu tahun kedepan terhadap harga saham penutupan bank BNI, BRI, BTN dan Mandiri dengan menggunakan data historis harian saham 2015. Hasil prediksi untuk satu minggu dan satu bulan ditahun 2016 sudah terjadi (sudah ada), dan sesuai dengan hasil prediksi pada penelitian ini bahwa peluang kenaikan harga saham yang paling tertinggi diantara harga saham bank BNI, BRI, BTN dan Mandiri untuk periode satu minggu dan satu bulan adalah bank Mandiri.

\section{Kesimpulan}

1. Pada learning problem dengan Algoritma Baum-Walch kemungkinan peluang kenaikan harga saham paling tertinggi pada periode satu minggu dan satu bulan kedepan yaitu bank Mandiri, sedangkan untuk periode satu tahun kedepan yaitu bank BRI.

2. Untuk decoding problem dengan menggunakan algoritma Viterbi, dapat diambil kesimpulan bahwa untuk tahun 2016 kemungkinan peluang harga saham dari bank BNI, BRI, Mandiri dan BTN akan lebih banyak turun. walaupun akan lebih banyak turun tidak akan menutup kemungkinan untuk peluang kenaikan harga saham BRI pada tahun 2016 akan mengalami kenaikan.

\section{Daftar Pustaka}

[1] Martinno, T. Y. 2013. Perancangan Program Hidden Markov Model dan Principal Component Analysis Untuk Peramalan Harga Harian Saham. Universitas Bina Nusantara. Jakarta.

[2] Firdaniza, dkk. 2006. Hidden Markov Model. Universitas Padjadjaran. Jawa Barat.

[3] Ross, Sheldon M. 2012. Introduction to Probability Model. Edition Tenth. Pearson Education, Inc. America.

[4] Ghahramani, Z. 2001. An Introduction Hidden Markov Models and Bayesian Network. International Journal of Pattern Recognition and Artifizial Intelligence. 15(1):9-42.

[5] Fonzo, V.D., F.A. Pentini and V. Parisi. 2007. Hidden Markov Models in Bioinformatics. Bentham Science Publishers Ltd. 2(1) : 49 - 61.

[6] Rabiner, L.R. 1989. A Tutorial on Hidden Markov Models and Selected Aplications in Speech Recognition, Proceedings of The IEEE, 77(2) : 257-286. 